\title{
NEKK AND PCI NETWORK
}

\author{
Friday, June 5
}

13:00-16:30 Nordisk Elektrokardiografisk Klub (NEKK)

Main Hall

Nordic Working Group on Pacing and Electrophysiology (NEKK) meeting

Theme: Ventricular arrhythmias

Chairmen: Gizur Gottskalksson (IS), Karl Heinz Kuck (DE)

13:00-14:30 What is the role of the electropysiology study in the evaluation of ventricular arrhythmias in 2009

Per Blomström (SE)

ICD therapy for primary prevention af ventricular arrhythmias

Gerhard Hindricks (DE)

The cardiac Purkinje system and ventricular arrhythmias

David O. Arnar (IS)

14:30-15:00 Coffee break

15:00-16:30 The Long QT Syndrome - an update

Lauri Toivonen (FI)

The role of radiofrequency ablation in therapy of VT/VF syndromes

Karl Heinz Kuck (DE)

Medical therapy for VT/VF syndromes, when and what drugs?

Jens Cosedis Nielsen (DK)

This event is sponsored by Biotronik

Open for all participants 
Friday, June 5

13:00-16:30 The Nordic Baltic PCI Network

13:00-14:30 Research in invasive cardiology in the NB region - time for further collaboration?

Upcoming and ongoing research projects overview - Leif Thuesen (DK)

SCAAR and SWEDEHEART

Elmir Omerovic (SE)

Collaboration in $\mathrm{PCl}$ registries across national borders

Thorarinn Gudnason (IS)

Vestdansk registry

Anne Kaltoft (DK)

Sort-out study

Lisette Okkels (DK)

NIVUS - Nordic Intravascular Ultrasound in stent thrombosis and Restenosis

Saila Vikmann (FI)

Bifurcation study

Matti Niemelä (FI)

Apical vs surgical biologic aortic valve replacement in patients over 70 years of age

Leif Thuesen (DK)

Substudies of the bifurcation study

Andrejs Erglis (LV)

Norwegian Coronary Stent Trial (NorStent)

Jan Erik Nordrehaug (NO)

14:30-15:00 Coffee Break

15:00-16:30 Left main disease - stent or surgery

Nordic-Baltic-British Left main stenosis CABG vs PCI

Timo Makikalio (FI)

The SYNTAX trial and its impact, the inteventionalist's view

Per Albertsson (SE)

The SYNTAX trial and its impact, the surgeon's view

Anders Jeppsson (SE) 


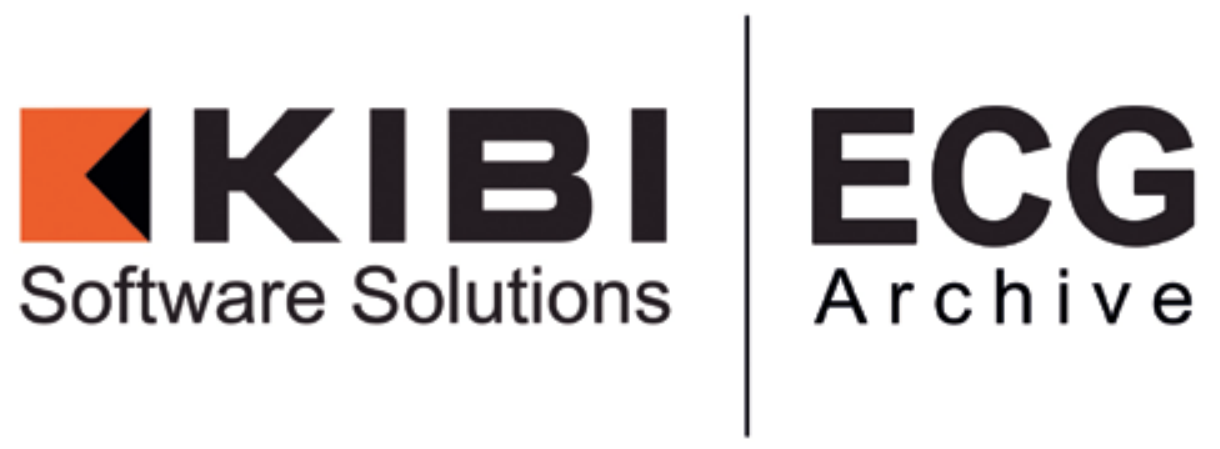

\section{Effective ECG archiving solution for multi-vendor environments}

Kibi Software Solutions has launched a new solution package for the Kibi Forte platform that allows the use of a light archive for effective storing and retrieving of ECG records as the need arises during treatment. Patient records can be stored directly into an electronic archive in a centralised and device-independent manner, after which they are seamlessly available through electronic medical journals.

The system makes device independence possible. The records can be PDF files or similar image-based presentations, but the added clinical value lies in the ability to archive original or derived discrete data $(. \mathrm{xml})$ so that it can be used on a daily basis. The Kibi Forte ECG viewer application supports most discrete formats. New integrations are implemented as necessary.

\section{Keywords}

Access to ECG recordings regardless the origin or format through EMR system

Capability to make measurements on screen (amplitude and time calibers) of discrete. $\mathrm{xml}$ data

ECG recording device, brand and vendor independency, ideal for multi-vendor environment

Scalable from small installation to regional ECG archive, from private clinic to ambulance solutions

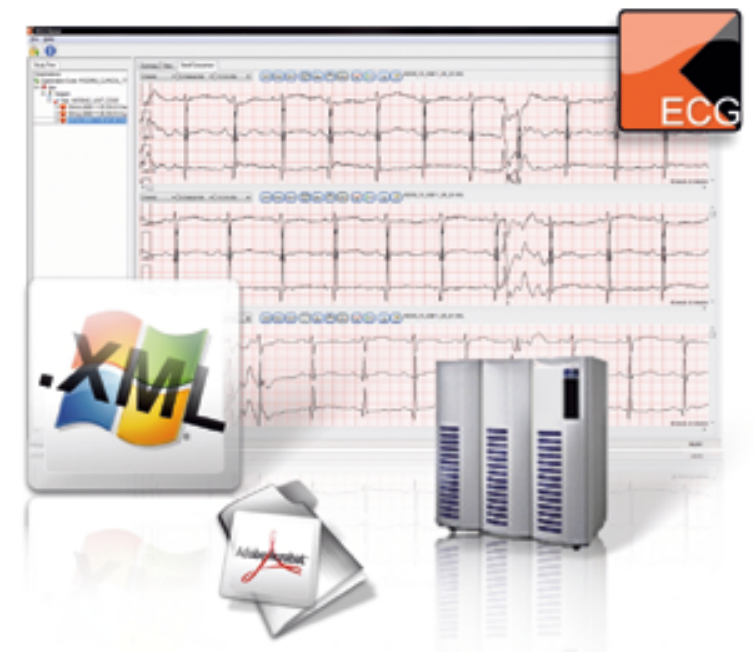

\section{For more information about our ECG solutions please visit our booth at NBCC2009 or visit http://www.kibi.eu}

